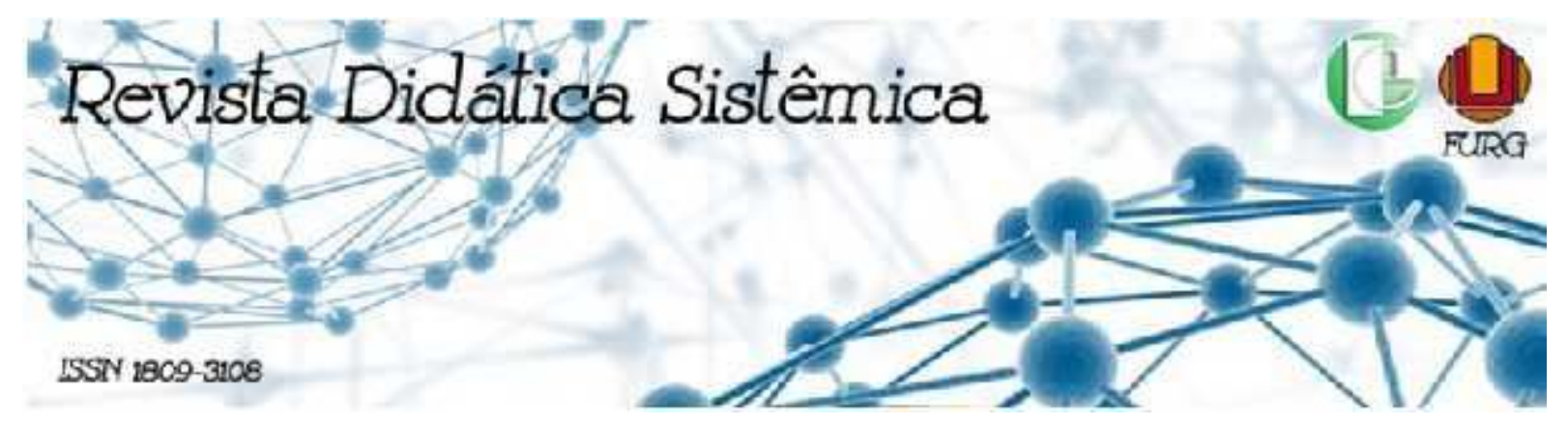

\title{
A EDUCAÇÃO FÍSICA INTEGRADA À EDUCAÇÃO INFANTIL NO DISTRITO FEDERAL: CONSIDERAÇÕES ACERCA DO PROGRAMA "EDUCAÇÃO COM MOVIMENTO"1
}

\author{
Graciele Pereira Lemos ${ }^{2}$ \\ Jonatas Maia da Costa ${ }^{3}$
}

\section{RESUMO}

Este texto apresenta as bases normativas do Programa Educação com Movimento. Uma iniciativa que, no contexto da educação pública do Distrito Federal, incorpora a educação física nos projetos políticopedagógicos de escolas da educação infantil. Almeja-se que o professor de educação física realize um trabalho integrado e interdisciplinar junto aos pedagogos na educação das crianças pequenas. Parte da história da educação pública da capital federal contextualiza o texto, antes de recuperar que a Educação com Movimento tem sua gênese em condicionantes histórico-políticos favoráveis. Sua constituição se deve aos avanços curriculares progressistas que o Distrito Federal viveu em meio à construção coletiva de um currículo. Notadamente, o programa anseia por um desenvolvimento em compasso com as suas diretrizes que sugerem, como auspiciosas, as contribuições da educação física na educação da infância na escola pública.

Palavras-chave: Educação Física; Educação Infantil; Currículo; Escola Pública.

\section{PHYSICAL EDUCATION INTEGRATED WITH CHILD EDUCATION IN THE FEDERAL} DISTRICT: CONSIDERATIONS ABOUT THE “EDUCATION WITH MOVEMENT” PROGRAM

\section{ABSTRACT}

This text presents the normative bases of the Education with Movement program. An initiative that, in the context of public education in the Federal District, incorporates physical education in the politicalpedagogical projects of child education schools. The intention is that the physical education teacher does an integrated and interdisciplinary work with pedagogues in the education of children. Part of the history of public education in the federal capital contextualizes the text, before recovering that Educação com Movimento has its genesis in favorable historical-political conditions. Its constitution is linked to the progressive curricular advances that the Federal District experienced during the collective construction of a curriculum. Notably, the program looks forward to a development in communion with its guidelines that suggest the contributions of physical education in child education in public schools are auspicious.

Keywords: Physical education; Child education; Curriculum; Public school.

\footnotetext{
${ }^{1}$ Texto elaborado a partir da dissertação intitulada "A educação física na educação infantil do Distrito Federal: uma experiência em construção", defendida no âmbito do Programa de Pós-Graduação em Educação Física da Universidade de Brasília.

${ }^{2}$ Mestre em Educação Física pela Universidade de Brasília. Professora da Secretaria de Educação do Distrito Federal. E-mail: gracilemosmartins@gmail.com

${ }^{3}$ Doutor em educação pela Universidade de Brasília. Professor da Faculdade de Educação Física da Universidade de Brasília. E-mail: jonatascosta01@gmail.com
} 


\title{
EDUCACIÓN FÍSICA INTEGRADA CON EDUCACIÓN INFANTIL EN EL DISTRITO FEDERAL: CONSIDERACIONES SOBRE EL PROGRAMA "EDUCACIÓN CON MOVIMIENTO"
}

\begin{abstract}
RESUMEN
Este texto presenta las bases normativas del programa Educación con Movimiento. Una iniciativa que, en el contexto de la educación pública en el Distrito Federal, incorpora la educación física en los proyectos político-pedagógicos de las escuelas de educación infantil. La intención es que el docente de educación física haga un trabajo integrado e interdisciplinario con los pedagogos en la educación de los niños. Parte de la historia de la educación pública en la capital federal contextualiza el texto, antes de recuperar que Educação com Movimento tiene su génesis en condiciones histórico-políticas favorables. Su constitución está vinculada a los avances curriculares progresivos que experimentó el Distrito Federal durante la construcción colectiva de un currículo. En particular, el programa espera un desarrollo en comunión con sus directrices que sugieren que las contribuciones de la educación física en la educación infantil en las escuelas públicas son auspiciosas.
\end{abstract}

Palabras clave: Educación Física; Educación Infantil; Currículum; Escuela pública.

\section{INTRODUÇÃO}

O Programa Educação com Movimento (PECM), objeto de estudo que permeia o escopo deste trabalho, tem sido a aposta progressista ${ }^{4}$ da Secretaria de Estado de Educação do Distrito Federal (SEEDF) na procura de salvaguardar a presença do professor de educação física como um parceiro do professor pedagogo na escola de crianças pequenas. Trata-se de uma iniciativa que recupera uma experiência histórica importante da educação do Distrito Federal (DF), vivida ao final da década de 1990, e logo interrompida em face às contingências políticas na capital da república. O fato é que, após a criação, em 2013, de um novo currículo de base crítica, foi possível integrar a educação física ao currículo da formação de crianças pequenas na rede pública de ensino.

Já à partida é importante destacar, em termos de concepção epistemológica e pedagógica, nossa aderência à teoria social ${ }^{5}$ e seus desdobramentos na educação e, em especial, na educação física. Do ponto de vista de cientificidade, nossa prática se ancora em um duplo compromisso ético-humanista: aquele que nos permita uma constante busca pela verdade histórica e, ao mesmo tempo, por avanços que coloquem o conhecimento em perspectiva de uma real possibilidade de transformação social. Nesse sentido, o presente texto é fruto de uma

\footnotetext{
${ }^{4}$ O termo "progressista" carrega, aqui, uma conotação que sugere "reforma". No caso, trata-se de mudanças sobre aquilo que está posto no âmbito das políticas educacionais do Distrito Federal, de forma a superar determinadas concepções e práticas pedagógicas.

${ }^{5}$ Refere-se à perspectiva marxiana de compreensão do mundo. Sob tal perspectiva, os pesquisadores são sujeitos ativos no processo de produção científica, porém com uma postura de máxima fidelidade ao objeto. Em Marx, se aprende que cabe ao sujeito (que investiga) "(...) apoderar-se da matéria, em seus pormenores, de analisar suas diferentes formas de desenvolvimento e de perquirir a conexão existente entre elas” (MARX, 2013, p. 90).
} 
intenção político-pedagógica que nasce na educação pública do Distrito Federal (DF) e vocaliza o anseio de professores de educação física em se colocar como agentes importantes da educação do corpo desde a infância na escola. Não se trata, aqui, de uma ação meramente corporativista da educação física no interior da rede pública de ensino. Em que pese haver, de fato, um braço conservador da área, que tem procurado instituir a educação física, na escola pública, por meio de força política ${ }^{6}$, a despeito da necessária justificativa pedagógica que a integre a um projeto de escola republicana. Ademais, tão pouco quer, aqui, retomar a consagrada "educação compensatória", que tanto marcou a história da educação infantil no Brasil (KUHLMANN JR, 2000; KRAMER, 2003; GUIMARÃES, 2017). Portanto, o que o PECM pretende é que, por meio do trabalho integrado entre estes dois importantes atores pedagógicos e áreas de conhecimento (educação física e pedagogia), se estabeleça uma metodologia de ensino interdisciplinar - algo muito caro à educação da infância.

Há, ainda, um segundo objeto que comparece e que se articula ao PECM. Trata-se da educação infantil. Em que pesem os avanços do ponto de vista científico e da formação acadêmica da área, a educação física praticamente inexiste, na educação infantil, no contexto do Distrito Federal. Quando muito, experiências, nesta etapa de ensino, se apresentam, exclusivamente, como práticas corporais em atividades extracurriculares, quase sempre presentes no universo de escolas privadas da elite como forma de compor projetos de educação de tempo integral (TREVISAN, 2017). Logo, a pesquisa que permitiu a elaboração deste texto tenciona concorrer na aproximação da educação física como linguagem a ser experimentada na educação infantil. Obviamente, isso requer uma apropriação da área no âmbito de sua formação que tenda a apreender os condicionantes de natureza pedagógica que compõem um projeto para a educação infantil na escola pública.

Sendo assim, o propósito deste texto, em específico, foi o de fornecer um conjunto de informações que esclarece o desenvolvimento atual do PECM, iniciativa que permitiu - como já mencionado - a inserção da educação física, para as crianças, na escola pública do DF. Do ponto de vista metodológico, situa-se no âmbito de uma pesquisa documental, de abordagem qualitativa (SEVERINO, 2007). No caso, documentos de natureza pedagógica que perfazem o currículo do Distrito Federal bem como aqueles que configuram as diretrizes do PECM foram analisados a fim de elucidar o seu alcance em termos de organização do trabalho pedagógico

\footnotetext{
${ }^{6} \mathrm{O}$ sistema CREF/CONFEF tem procurado, por meio de iniciativas políticas, como lobby junto a deputados da Câmara Legislativa, do DF, assegurar, por força de lei, a presença do profissional de educação física na escola de educação infantil e anos inicias, do ensino fundamental, na rede pública do DF.
} 
da educação física para a educação infantil.

Ao fim e ao cabo, a discussão do avanço PECM, tendo, no horizonte, sua consolidação, é algo desejável e se justifica na construção de uma escola pública de concepção ampliada e de orientação política progressista. Entendemos que, para tanto, será necessário incorporar a sua realização projetos que avaliem, permanentemente, suas ações no sentido de cada vez mais qualificá-lo. Em nosso caso, tudo que, aqui, se encontra consignado, é fruto deste anseio e, por meio de pesquisa científico-acadêmica, logrou êxito na sistematização desta importante diligência da rede pública de ensino do DF.

\section{EDUCAÇÃO NO DISTRITO FEDERAL: BREVE CONTEXTUALIZAÇÃO}

É notadamente conhecido que Brasília nasceu ${ }^{7}$ como uma cidade planejada. Seus traços arquitetônicos, sua estrutura funcional organizada em setores e suas quadras residenciais agrupadas evidenciam essas características planificadas. No âmbito da educação pública, Brasília é, também, expressão de vanguarda que passou pela mesma lógica de um planejamento que revela uma intenção político-pedagógica. Em 1957, Anísio Teixeira, expoente educador e político brasileiro, fora convidado, durante a construção de Brasília, por Ernesto Silva, presidente da Companhia Urbanizadora da Nova Capital do Brasil (NOVACAP), a elaborar o plano de construção escolar da nova capital federal (ROCHA, 2002). Logo, sendo Anísio uma das figuras mais importantes do escolanovismo brasileiro (SAVIANI, 2013), o ideal pedagógico traduzido em proposta, para a capital, terá evidentes marcas progressistas.

Havia, portanto, um ambiente histórico favorável à presença da educação física na formação de crianças na capital do País. Anísio trouxe, para Brasília, uma experiência iniciada em Salvador, no final da década de 1940, quando o mesmo havia sido secretário de educação da capital baiana (SAVIANI, 2013). Naquela oportunidade, ele criara o Centro Educacional Carneiro Ribeiro, considerado o primeiro centro de educação popular do Brasil (NUNES, 2009). A concepção pedagógica deste empreendimento escolar, quando trazida para Brasília, irá resultar nas chamadas Escolas Parques.

É certo, portanto, que a educação física compareceu no currículo das crianças por meio do ensino primário desde a idealização do plano educacional de Brasília. No caso, a educação

\footnotetext{
${ }^{7}$ Brasília foi fundada em 21 de abril de 1960, durante o governo de Juscelino Kubitschek. A cidade, que é a expressão integrada das obras do arquiteto Oscar Niemeyer e do urbanista Lúcio Costa, foi, em 1987, inscrita pela UNESCO como patrimônio cultural da humanidade.
} 
física se apresentava como disciplina nos anos iniciais do Ensino Fundamental (antigo primário), no Distrito Federal, por meio da Escola Parque. Tal escola era, de fato, uma proposta inovadora, com foco no desenvolvimento integral das crianças a partir de uma abordagem aberta e multidisciplinar, envolvendo o ensino das artes e da educação física em um único espaço físico. As demais disciplinas eram ofertadas aos estudantes em outra escola, as chamadas Escolas Classes, nas quais havia um professor generalista, denominado professor de atividades - em sua maioria, formado por professoras normalistas e pedagogas. Tratava-se, inclusive, de um esforço de empreender uma educação em tempo integral, quando o estudante, num período, frequentava a Escola Classe e, no contraturno, a Escola Parque. Entretanto, as Escolas Parques não foram implantadas conforme as ideias originais de Anísio. Das 28 escolasparques previstas, apenas 5 foram, de fato, implementadas em Brasília (PEREIRA; ROCHA, 2011).

O resultado disso, no tocante à educação física, foi ter destinado o tempo pedagógico das aulas para a própria Escola Classe, na maior parte das vezes, sem infraestrutura adequada, cuja responsabilidade estaria a cargo, exclusivamente, da professora de atividades. Por tudo isso, a rede pública de ensino do DF, em grande medida, ofertou as aulas de educação física com professores de educação física somente a partir dos anos finais do Ensino Fundamental e durante o Ensino Médio.

\section{GÊNESE DO PROGRAMA EDUCAÇÃO COM MOVIMENTO}

Somente em 1996, num contexto político favorável ${ }^{8}$, toma corpo uma proposta que procurava viabilizar aos estudantes dos anos iniciais do Ensino Fundamental o contato com a educação física por meio de professor especialista, que, por sua vez, tratasse a educação física como componente curricular integrado ao projeto político-pedagógica da escola, tal qual preconizava a Lei de Diretrizes e Bases da Educação Nacional estabelecida em 1996 (BRASIL, 1996). Essa iniciativa, intitulada Projeto Núcleos (o nome realmente é esse) de Educação com Movimento, estava sintonizada com os princípios da Escola Candanga ${ }^{9}$ e teve sua elaboração

\footnotetext{
8 À frente do governo do Distrito Federal estava Cristovam Buarque, figura política que havia sido reitor da Universidade de Brasília e era reconhecido por ser um entusiasta das políticas de educação. Cristovam, eleito pelo Partido dos Trabalhadores (PT), governou o Distrito Federal entre 1995 e 1998.

${ }^{9}$ Proposta Político Pedagógica construída no governo do Cristovam Buarque para a educação pública no DF, fundamentada em princípios teóricos e em diversas dimensões: sociológica (cidadania e democracia), filosófica (ética e ecologia), pedagógica (estrutura curricular organizada em fases de formação), epistemológica (desenvolvimento e aprendizagens contínuos, construção coletiva e social do conhecimento) e política (questiona a realidade existente e aponta mecanismos para superação).
} 
realizada de forma conjunta pelos professores de educação física, representantes da Divisão de Ensino Fundamental da Fundação Educacional, diretores de escolas, representantes de Conselho Escolares, representantes da Associação dos Professores de Educação Física do Distrito Federal (APEF-DF) e do Sindicato dos Professores do Distrito Federal (SAMPAIO; LIAO JUNIOR, 1999).

Paulo Freire se configura como uma das referências centrais da proposta, que tinha abordagem teórica fundamentada em três pressupostos: a) oferecer aos estudantes, dentro das possibilidades, o que a humanidade acumulou em termos de movimentos corporais de forma crítica e contextualizada; b) relacionar toda essa vivência corporal historicamente acumulada à construção de conceitos, valores e identidades presentes nos conteúdo das diversas disciplinas, fortalecendo, assim, a conquista de um espaço interdisciplinar que envolva todos os educadores do núcleo; c) adequar os métodos, conteúdos e procedimentos aos interesses e ao desenvolvimento dos estudantes (SAMPAIO; LIAO JUNIOR, 1999).

$\mathrm{O}$ projeto chegou a ser implantado em 50 escolas. À época, isso, provavelmente ${ }^{10}$, correspondia a $13 \%$ do total das escolas públicas que atendiam aos anos iniciais do ensino fundamental do DF. Em 1999, com a troca de governo ${ }^{11}$, o projeto foi perdendo força. Apenas duas escolas conseguiram dar continuidade, mesmo em meio às dificuldades, quais sejam, a Escola Classe 15 e a Escola Classe 18 de Taguatinga ${ }^{12}$, as quais se tornaram referência dessa experiência. (DISTRITO FEDERAL, 2012).

Em 2011, a partir de nova conjuntura política favorável ${ }^{13}$, por ocasião da elaboração de um novo currículo da $\operatorname{SEEDF}^{14}$ e durante as plenárias regionais realizadas para a discussão da

\footnotetext{
${ }^{10}$ Dados do ano 2000 obtidos a partir do censo de 2001. Não foram encontrados dados específicos de anos anteriores.

${ }^{11}$ Apesar de amplo favoritismo (Cristovam venceu no primeiro turno) e do reconhecimento de que havia feito um governo paradigmático no DF, Cristovam Buarque foi derrotado, nas eleições de 1998, por Joaquim Roriz do PMDB. Roriz foi o último "governador biônico" do DF entre os anos de 1988 a 1990. Em 1991, tornou-se o primeiro governador eleito do DF. Tempo que repercutia os avanços da Constituição de 1988 que concedeu autonomia política à capital federal. Nas eleições de 1994, Cristovam derrotou o candidato rorizista Valmir Campelo (PMDB), mas, quatro anos depois, o seu bom governo, na área de educação, não foi suficiente para derrotar o capital político de Roriz no DF.

${ }^{12}$ Taguatinga é uma das 31 regiões administrativas que perfazem o Distrito Federal.

${ }^{13}$ Após um hiato de 12 anos, o PT voltava ao poder na capital federal. Elegeu-se Agnelo Queiroz, que havia sido ministro da pasta do esporte durante o primeiro mandato do presidente Lula. Agnelo governou o DF entre $2011 \mathrm{e}$ 2014. Em que pese ter feito um mandato recheado de contradições para o campo democrático e popular no que tange à pauta da educação, houve avanços.

${ }^{14}$ Tratava-se um momento histórico de discussão que resultou no Currículo em Movimento. Para saber mais sobre este processo, recomendamos a leitura da dissertação de mestrado da professora da SEEDF, Juliana Oliveira Freire, intitulada Educação física escolar em Brasília: análise comparativa de currículos dos anos iniciais do ensino fundamental", defendida no Programa de Pós-graduação em Educação Física, da UnB, no ano de 2016, orientada pela professora Ingrid Wiggers.
} 
parte específica da educação física, os professores participantes ressaltaram a importância de um trabalho integrado entre o professor de educação física e o professor de atividades para os anos inicias do Ensino Fundamental - obviamente, era uma clara alusão à experiência vivida até 1998. A reboque desse debate, a incorporação da educação infantil também foi amplamente defendida, embora não tenha sido incluída na experiência de desenvolvimento piloto do então "Projeto de Educação com Movimento". Este funcionou sob aprovação da Coordenação de Ensino Fundamental e da Subsecretaria de Gestão dos Profissionais da Educação, em 5 escolas, para subsidiar uma avaliação do mesmo, com vistas à expansão no ano seguinte. (DISTRITO FEDERAL, 2011)

Em 2012, este que se apresentava ainda como um projeto-piloto, foi reestruturado. A proposta visava atender, somente, as turmas de anos iniciais do Ensino Fundamental, a despeito do anseio de se ver a educação infantil contemplada. Num primeiro momento, concedeu-se o projeto em uma escola-polo em cada regional de ensino, nos turnos matutino e vespertino. As escolas, preferencialmente, deveriam atender às classes de correção da distorção idade/série, a fim de que, de forma interdisciplinar, promovesse a formação integral do estudante, ampliando o seu repertório de experiências corporais mediante a intervenção pedagógica de um professor especializado nesta área, no caso, o professor de educação física. A previsão era de selecionar 26 professores efetivos de educação física para participar desta expansão no ano de 2013, sendo que 13 professores teriam regência matutina, e os outros 13, regência vespertina. (DISTRITO FEDERAL, 2012).

O desenvolvimento do PECM esteve, inicialmente, vinculado ao Projeto Político Pedagógico Professor Calos Mota e, na concepção de Educação Integral, apresentados no Currículo em Movimento, proposta de educação do Governo do Distrito Federal/SEEDF consolidada no ano de 2013. (DISTRITO FEDERAL, 2012). CONFUSO (A concepção de Educação Integral, representada pelo PROEITI "Projeto de Educação Integral em Tempo Integral e o Projeto Político Pedagógico Professor Carlos Mota, ambos de 2012, subsidiam o PECM e são referenciados no Curriculo em Movimento do Distrito Federal de 2014.)

A expansão do PECM aconteceu progressivamente. Tal expansão permitiu que, em 2014, finalmente, passasse a atender, também, a educação infantil, inserindo-se no planejamento das políticas públicas educacionais constantes no Plano Distrital de Educação (PDE), no Plano Plurianual do Governo do Distrito Federal 2016-2019 (PPA) e no planejamento estratégico da SEEDF 2015-2018. (DISTRITO FEDERAL, 2017). Fato que entendemos como um processo de legitimação e institucionalização do PECM. Ou seja, trata- 
se das bases normativas que buscam reconhecê-lo como parte da política educacional da SEEDF. Portanto, se, por um lado, a educação infantil não esteve presente na idealização original nem na retomada das ideias pedagógicas contidas no PECM, por outro, ela compôs com os anos iniciais do ensino fundamental - um momento no qual tal política supera sua condição de projeto para, então, se situar como um programa educacional. Por hipótese, vale considerar o anseio de docentes de que a educação infantil estivesse, desde o início da retomada do PECM foi um dos determinantes na institucionalização do programa. Ora, a verificação de que o PECM se fez presente no conjunto de documentos supracitados, sugerindo que o mesmo transcendeu uma política focalista e transitória. Atualmente, o PECM vigora a despeito dos retrocessos eleitorais no $\mathrm{DF}^{15}$.

Os objetivos gerais e específicos, do PECM, consistem em:

"(...) implantar e implementar PECM na Educação Infantil e nos Anos Iniciais do Ensino Fundamental da rede pública de ensino do Distrito Federal, na intenção de ampliar as experiências corporais dos estudantes, mediante a intervenção pedagógica integrada e interdisciplinar entre o professor de Atividades e o professor de Educação Física na perspectiva da Educação Integral, conforme preconizado no Currículo em Movimento da Educação Básica do Distrito Federal.

Os objetivos específicos se baseiam em:

Explorar os conteúdos da cultura corporal de movimento presentes na Educação Física, tais como: o jogo, a brincadeira, o esporte, a luta, a ginástica, a dança e conhecimentos sobre o corpo, integrando-os aos objetivos, linguagens e conteúdos da Educação Infantil e dos Anos Iniciais do Ensino Fundamental;

Estimular a interdisciplinaridade na intervenção pedagógica do professor de Educação Física, por meio do planejamento e atuação integrada ao trabalho do professor de Atividades, em consonância com o projeto políticopedagógico da escola e com o Currículo em Movimento da Educação Básica; Fortalecer o vínculo do estudante com a escola, considerando as necessidades da criança de brincar, jogar e movimentar-se, utilizando as estratégias didático-metodológicas da Educação Física na organização do trabalho pedagógico da escola;

\footnotetext{
${ }^{15}$ Rodrigo Rollemberg foi eleito governador do DF pelo Partido Socialista Brasileiro (PSB), em substituição a Agnelo Queiroz. Rollemberg governou entre 2015 e 2018. Ele se omitiu na ocasião do golpe de 2016 e fez isso em nome da dependência do DF ao fundo constitucional - preferiu estar ao lado de Michel Temer, como é possível verificar em entrevista ao Correio Braziliense: https://www.correiobraziliense.com.br/app/noticia/politica/2016/09/04/interna_politica,547222/aposimpeachment-rodrigo-rollemberg-diz-que-isso-e-pagina-virada.shtml Atualmente, o DF é governado por Ibaneis Rocha, do MDB. Ibaneis foi eleito, em 2018, na esteira do conservadorismo e da emergência do bolsonarismo no País. A expressão maior do alinhamento do atual governador às ideias do presidente da república se materializa na política educacional que fez nascer no DF, a militarização das escolas (MENDONÇA, 2019).
} 
Contribuir para a formação integral dos estudantes, por meio de intervenções corporais pedagógicas exploratórias e reflexivas, com base em valores, tais como: respeito às diferenças, companheirismo, fraternidade, justiça, sustentabilidade, perseverança, responsabilidade, tolerância, dentre outros, que constituem alicerces da vida em sociedade e do bem-estar social." (DISTRITO FEDERAL, 2018, p. 9).

A educação física, na SEEDF, é orientada, desde 2013, pelo Currículo em Movimento da Educação Básica. Esse currículo apresenta as concepções, objetivos e conteúdos das etapas e de cada modalidade da educação básica. Nesse sentido, o currículo foi sistematizado e dispõe de oito cadernos específicos a cada etapa ou modalidade de ensino: o de pressupostos teóricos, o de educação infantil, o dos anos iniciais do ensino fundamental, dos anos finais, do ensino médio, da educação profissional e a distância, da educação de jovens e adultos e, finalmente, da educação especial. Por sua vez, o PECM, também, possui um caderno que, anualmente, é atualizado, no qual constam as orientações para o seu funcionamento nas escolas. SOMAR EDUCAÇÃO PROFISSIONAL COM A DISTÂNCIA $i$ - o caderno do currículo em movimento que trata da educação profissional também trata da educação a distância, porém nem toda a modalidade de educação profissional é realizada a distância e a educação a distância não acontece apenas no ensino profissional.

Uma das orientações basilares do PECM é o trabalho conjunto entre o professor de atividades e o professor de educação física. Isso se tornou algo muito caro ao êxito de seus pressupostos. Destarte, espera-se que eles compartilhem conhecimentos, registrem dificuldades, observem diferenças e as diversidades intrínsecas ao processo de ensinoaprendizagem no contexto escolar. Essa "troca" entre os professores favorece a possibilidade de que o planejamento alcance a interdisciplinaridade e torne o trabalho pedagógico, na escola, mais efetivo, tanto para os estudantes quanto para os professores. (DISTRITO FEDERAL, 2018).

\section{O PROGRAMA EDUCAÇÃO COM MOVIMENTO E A EDUCAÇÃO INFANTIL}

Quanto à educação infantil, os apontamentos do PECM reafirmam a forma de organização escolar a partir de um eixo integrador que agrupam o educar, o cuidar, o brincar e o interagir. Isso implica um trabalho que contemple o "faz de conta", os jogos e as brincadeiras que permitem a criança desenvolver suas potencialidades, recriar suas experiências, percepções, sentimentos e pensamentos, convergindo tarefas de ordem cognitiva, emocional, 
motora e social. (DISTRITO FEDERAL, 2018).

Com relação à organização do trabalho pedagógico do professor que atua na educação infantil, a orientação é de que se observem os elementos que compõem a rotina, o ambiente escolar, os materiais, os espaços e os tempos dedicados às crianças. O trabalho pedagógico, nesse nível de ensino, precisa considerar as necessidades das crianças. A organização curricular da educação infantil ${ }^{16}$ está baseada nas linguagens e práticas sociais, o que permite o trabalho multidimensional das crianças, possibilitando a compreensão de mundo e a produção de novos significados, a partir de suas vivências pessoais. Assim, o PECM deve contribuir para a construção da identidade da criança, proporcionando experiências corporais que valorizem a diversidade e a convivência saudável. (DISTRITO FEDERAL, 2018).

Consta, nas orientações do PECM, que a sistematização do planejamento do professor de educação física, integrado ao trabalho pedagógico do professor de atividades, esteja registrada no projeto político-pedagógico da escola. Tal registro confere uma consistência didático-pedagógica e coerência para a intervenção do professor de educação física no âmbito da unidade escolar. Esse registro deve ser acompanhado da avaliação anual do PECM, o qual prevê que, ao final de cada ano, o professor de educação física solicite à direção, aos professores e às crianças uma avaliação de seu trabalho, com o intuito de identificar as fragilidades e as potencialidades no desenvolvimento do PECM na instituição que o recebe. (DISTRITO FEDERAL, 2018). A dimensão desta exigência não se situa com uma conotação meritocrática do trabalho docente. Nesse sentido, a avaliação se estabelece em seu caráter de constatação da realidade pedagógica vivida por diversos atores. Contudo, o documento é omisso em relação às formas de avaliação. É preciso identificar, por meio de estudos e de pesquisa, como tem sido a participação das crianças atendidas no PECM e de que forma elas conseguem participar desse processo.

O PECM possui sete princípios de funcionamento, a saber:

$1^{\circ} \mathrm{O}$ atendimento do professor de Educação Física na Educação Infantil e/ou nos Anos Iniciais do Ensino Fundamental deverá primar, em todos os casos, pelo planejamento conjunto com o professor de Atividades e

\footnotetext{
${ }^{16}$ Este texto faz menção à primeira versão do Currículo em Movimento, do Distrito Federal, de 2014. Atualmente, está em vigor a segunda versão de Dezembro/2018. Essa reestruturação aconteceu devido à necessidade de adequação do currículo à homologação da Base Nacional Comum Curricular (BNCC), para Educação Infantil, em 2017. Nossa predileção pela manutenção dos termos deste documento - e não do atual - guarda relação com a necessidade de salvaguardar, em forma de resistência, nossa preocupação com a incorporação da BNCC, sem os devidos apontamos críticos quando observamos que sua promulgação é parte da contrarreforma do Estado para as políticas educacionais na esteira do golpe de 2016.
} 
participação efetiva nos espaços de coordenação pedagógica. A intervenção pedagógica do professor de Educação Física deverá ser conjunta com o professor de Atividades, firmando uma atuação interdisciplinar;

$2^{\circ}-\mathrm{O}$ desenvolvimento do Projeto, quanto ao quantitativo e duração das aulas, na Educação Infantil e nos Anos Iniciais do Ensino Fundamental será organizado assim: duas intervenções semanais de 50 minutos cada, evitando-se aulas duplas ou em dias consecutivos;

$3^{\circ}$ - Nos Anos Iniciais do Ensino Fundamental será priorizado o atendimento das turmas de $5^{\circ}$ ano, expandindo para as turmas de $4^{\circ}, 3^{\circ}, 2^{\circ}, 1^{\circ}$ anos;

$4^{\circ}$ - Na Educação Infantil, deverão ser atendidos, prioritariamente, os estudantes do $2^{\circ}$ período ( 5 anos), expandindo, gradativamente, para o $1^{\circ}$ período (4 anos) e demais turmas da escola;

$5^{\circ}-\mathrm{O}$ professor de Educação Física atuará de acordo com as seguintes cargas horárias:

- Carga horária de 40 horas, em regime de jornada ampliada atendendo, no mínimo, dez (10) e, no máximo, quinze (15) turmas no turno de regência;

- Carga horária de 40 horas, em regime de 20h mais $20 \mathrm{~h}$ para as unidades escolares com até sete (7) turmas, por turno, garantida a coordenação pedagógica conjunta com os professores pedagogos;

- Carga horária de 20 horas para as unidades escolares com até sete (7) turmas, por turno.

$6^{\circ}$ - Caso perdure carga residual para o professor de Educação Física, caberá o desenvolvimento de projetos interdisciplinares, consoantes e constantes no PPP da unidade escolar.

$7^{\circ}$ - Caso a escola possua turmas de classe especial, o professor de Educação Física poderá atendê-las, desde que não ultrapasse o máximo de 15 turmas, observando-se sempre a possibilidade de inclusão nas turmas regulares de Educação Física. (DISTRITO FEDERAL, 2018, p. 21-22).

O documento reitera que esses princípios devem ser atendidos de forma hierárquica, do primeiro ao último, no momento de modulação da unidade escolar, com vistas a assegurar a qualidade da intervenção pedagógica. O não cumprimento desses princípios poderá acarretar o desligamento da unidade escolar do PECM ou a devolução do professor para sua respectiva regional de ensino. (DISTRITO FEDERAL, 2018).

Nas orientações do PECM, constam duas tabelas com a distribuição da carga horária, dos professores que fazem jornada ampliada ${ }^{17}$, elaboradas com vistas a assegurar o trabalho interdisciplinar, operacionalizando a inserção do professor de educação física na organização escolar da educação infantil e dos anos iniciais do Ensino Fundamental. Com isso,

\footnotetext{
${ }^{17}$ A jornada ampliada é uma organização administrativo-pedagógica da SEEDF, que regula o trabalho dos professores que possuem contrato de 40 horas. Trata-se de uma conquista da categoria, a qual preserva uma carga de regência, em sala de aula, num único turno, sendo o contraturno destinado ao planejamento, ao atendimento discente, à formação continuada, às reuniões coletivas e a outras atividades escolares que não sejam, especificamente, a de ensino.
} 
estabeleceram-se as rotinas da regência do professor em um dos turnos, garantindo o outro para realização das coordenações pedagógicas, cursos de formação continuada e realização das reuniões pedagógicas do próprio PECM. No entanto, essa sugestão não atende aos professores que possuem uma carga horária de trabalho organizada em regência de 20 horas e mais 20 horas. Tais professores possuem regência em sala nos dois turnos - matutino e vespertino. Para esses casos, orienta-se que as escolas promovam ajustes de acordo com seus projetos pedagógicos. (DISTRITO FEDERAL, 2018). Vale mencionar que essa forma de organização tem sido alvo de críticas por parte de alguns professores de educação física que não conseguem atender a todos os pressupostos pedagógicos do PECM. Tal crítica tem denunciado o prejuízo que há em torno do trabalho integrado e interdisciplinar entre professor de educação física e o de atividades, uma vez que tal organização dificulta o planejamento coletivo entre esses dois atores, colocando em risco o potencial pedagógico do programa.

Quanto à avaliação do trabalho realizado com as crianças, as orientações são para que o professor de atividades esteja presente nas aulas, não só observando, mas também participando de todas as intervenções pedagógicas. Pretende-se, assim, salvaguardar a parceria entre os professores, destinando ao processo de avaliação uma compreensão mais alargada das aprendizagens dos estudantes. (DISTRITO FEDERAL, 2018).

O PECM prevê que, ao final de cada ano, o professor de educação física deve elaborar um relatório em formato de portfólio. Ali, ele deverá apresentar todas as suas experiências desenvolvidas na escola. Trata-se de uma ação avaliativa de seu próprio trabalho educativo. Para tanto, são oferecidas orientações, tais como: avaliação do trabalho realizado pelo professor durante o ano, avaliação do PECM pelas crianças, pelos professores de atividades e pelos gestores. Espera-se que a sistematização desses documentos venha a subsidiar ações que visem qualificar o trabalho da educação física nas escolas da SEEDF (DISTRITO FEDERAL, 2018).

\section{CONSIDERAÇÕES FINAIS}

O PECM nos parece uma grande aposta. Uma aposta é sempre mais que uma mera hipótese e muito menos que uma inexorável certeza. Logo, o sentido que queremos dar a esta aposta, olhando para este objeto ainda pouco explorado cientificamente, é daquele que o observa como uma prática social concreta, construída, historicamente, em meio às tensões políticas vividas na própria SEEDF, que reverberam o desejo de um coletivo de professores, todos, servidores públicos. Permeado de contradições, reservará, no futuro, a continuação de 
uma construção coletiva que ora avançará, ora retrocederá. Porém, o mais importante é a sua materialização, na escola pública, do DF. Isso, sem dúvidas, desde nossa perspectiva, parecenos um avanço.

O fato de a educação infantil comparecer na esteira de uma política educacional que, inicialmente, estava orientada aos anos inicias do ensino fundamental, surge como um aspecto que complexifica ainda mais a iniciativa da SEEDF. Ora, é sabido que a educação infantil se apresenta com particularidades curriculares e orientações epistemológicas distintas àquelas consagradas no ensino fundamental. Não fosse apenas isso, há, também, as condições objetivas do trabalho que envolvem a educação infantil. Segundo dados do censo de 2018, a SEEDF contava com 28 Jardins de Infância e 34 Centros de Educação Infantil ${ }^{18}$ e, mesmo assim, isso não é suficiente para atender à demanda por creche e pré-escola do DF, de forma que não são raras as escolas de ensino fundamental a organizar turmas de educação infantil. A arquitetura dessas escolas nem sempre acompanham as necessidades dessa etapa educacional. De todo modo, compreendemos que a presença da educação infantil, no PECM, é um avanço no sentido de criar possibilidades pedagógicas cuja colaboração da educação física se efetive em toda a educação básica.

Neste trabalho, em específico, nosso alcance foi ainda bastante tímido. Talvez, tenha sido até incipiente frente àquilo que almejamos como projeto de investigação científicoacadêmico. Todavia, vale, ao menos, sobejar a iniciativa. O PECM carrega, em si, uma possibilidade de fazer a educação física avançar em torno de uma compreensão ampliada de educação. E isso está colocado em face ao suposto de que a prática educativa solicita um trabalho coletivo. Além disso, reivindica o reconhecimento dado aos ensinamentos da teoria histórico-cultural que advoga que as crianças aprendem com seus corpos. Logo, esse duplo eixo que configuram a concepção do PECM - interdisciplinaridade e educação do corpo - ilustram essa "aposta" que a educação física pode corroborar em certa medida, como protagonista na educação formal de crianças pequenas na escola pública.

A contar pela sua reemergência - posteriormente, a experiência da década de 1990 -, o PECM necessita se tornar objeto de pesquisa a partir de outros eixos de investigação. Aqui, ele foi alvo, exclusivamente, de sua relação com os documentos curriculares orientadores de sua realização. Embora o projeto de investigação ${ }^{19}$ que engendrou o presente estudo tenha

\footnotetext{
${ }^{18} \mathrm{Na}$ SEEDF, os Jardins de Infâncias são instituições que atendem, exclusivamente, à pré-escola. Os Centros de Educação Infantil possuem, além da pré-escola, as creches.

${ }^{19}$ Nota suprimida em razão de sua redação permitir a identificação da autoria. Caso o texto seja aceito pela revista, a nota aparecerá em sua íntegra.
} 
abordado, também, algumas experiências didático-pedagógicas concretas de professores de educação física, em tempo, deverão ser publicizadas em formato de artigo.

Há, nestes outros eixos de investigação, um potencial heurístico que, ao torná-los objetos de pesquisa, poderiam subsidiar novos projetos de investigação. Certamente, poderiam compor os desafios que se impõem ao trabalho da educação física escolar, especificamente, na rede pública de ensino do Distrito Federal. Uma convicção - mesmo que provisória - é de que a sua consolidação está condicionada à articulação dos desafios impostos pelo trabalho docente da educação física em se fazer presente de forma colaborativa à pedagogia e, sobretudo, a um projeto coletivo de escola. Nesses "novos projetos de investigação", caberia a prática pedagógica interdisciplinar, as condições objetivas e estruturais que possibilitam o atendimento de seus pressupostos teóricos e normativos, a necessária expansão e o atendimento universal das escolas públicas da SEEDF, o reconhecimento de um tempo e lugar de prática pedagógica próprios da educação física e não divergentes da educação infantil, entre outros tantos objetos de investigação que venham a se somar à intenção de se construir, cada vez mais, uma educação pública de qualidade e socialmente referenciada.

\section{REFERÊNCIAS}

BRASIL. Lei No 9.394, de 20 de dezembro de 1996. Estabelece as diretrizes e bases da educação nacional. Diário Oficial da União, Brasília, DF, dezembro, 1996.

DISTRITO FEDERAL. Educação Com Movimento: Educação Física nos anos iniciais. Brasília: SEDF/GDF, 2011.

DISTRITO FEDERAL. Educação com Movimento: Educação Física nos Anos Iniciais

PROJETO PILOTO. Brasília: SEDF/GDF, 2012.

DISTRITO FEDERAL. Currículo em movimento da educação básica: educação infantil. Brasília: SEDF, 2014.

DISTRITO FEDERAL. Educação com movimento: política de inserção do professor de Educação Física na Educação Infantil e Anos Iniciais do Ensino Fundamental. Brasília: SEDF/GDF, 2017.

DISTRITO FEDERAL. Educação Com Movimento: projeto de inserção do professor de Educação Física na Educação Infantil e nos Anos Iniciais do Ensino Fundamental. Brasília: SEDF/GDF, 2018.

GUIMARÃES, M. C. A história da atenção a criança e a infância no Brasil e o surgimento da creche e da pré-escola . Linhas, v. 18, n. 38, p. 80-142, 2017.

KRAMER, S. A política do pré-escolar no Brasil: a arte do disfarce. São Paulo: Cortez, 2003.

KUHLMANN JR, M. Histórias da Educação Infantil brasileira. Revista Brasileira de Educação, p. 5-18, 2000.

MARX, K. O capital: crítica da economia política. São Paulo: Boitempo, 2013.

MENDONÇA, E. F. Militarização de escolas públicas no DF: a gestão democrática sob ameaça. Revista

Brasileira de Política e Administração da Educação, v.35, n. 3, p. 594-611, set./dez. 2019. 
NUNES, C. Centro Educacional Carneiro Ribeiro: concepção e realização de uma experiência de educação integral no Brasil. Em Aberto, Brasília, 22, n. 80, abril 2009. 121-134.

PEREIRA, E. W.; ROCHA, L. M. D. F. Escola Parque de Brasília: uma experiência de educação integral. In: PEREIRA, E. W. Nas asas de Brasília: Memórias de uma utopia educativa (1956-1964). Brasília: Universidade de Brasília, 2011.

ROCHA, J. A. Anísio em Movimento. Brasília: Senado Federal, 2002

SAMPAIO, J. O; LIÁO JUNIOR, R. Projeto Núcleos de Educação com Movimento: A experiência do Distrito Federal, uma gestão democrática e popular. Revista Brasileira de Ciências do Esporte, v. 21 (1), p. 245-253, set 1999.

SAVIANI, D. História das ideias pedagógicas no Brasil. Campinas: Autores Associados, 2013.

SEVERINO, A. J. Metodologia do trabalho científico. São Paulo: Cortez, 2007.

TREVISAN, A. D. A educação física na educação infantil: apontamentos sobre os docentes em escolas públicas e privadas de Brasília. 45f. Monografia (Licenciatura em Educação Física) - Faculdade de Educação Física da Universidade de Brasília, Brasília, 2017. 